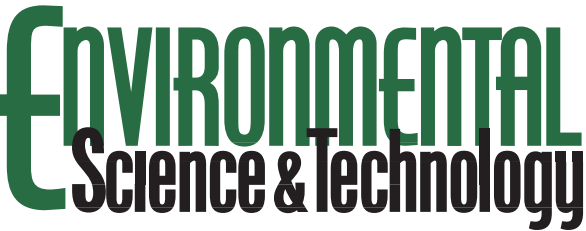

\section{Mapping Global Flows of Chemicals: From Fossil Fuel Feedstocks to Chemical Products}

\author{
Peter G. Levi*º and Jonathan M. Cullen \\ Department of Engineering, University of Cambridge, Trumpington Street, Cambridge, CB2 1PZ, United Kingdom \\ Supporting Information
}

\begin{abstract}
Chemical products are ubiquitous in modern society. The chemical sector is the largest industrial energy consumer and the third largest industrial emitter of carbon dioxide. The current portfolio of mitigation options for the chemical sector emphasizes upstream "supply side" solutions, whereas downstream mitigation options, such as material efficiency, are given comparatively short shrift. Key reasons for this are the scarcity of data on the sector's material flows, and the highly intertwined nature of its complex supply chains. We provide the most up to date, comprehensive and transparent data set available publicly, on virgin production routes in the chemical sector: from fossil fuel feedstocks to chemical products. We map global mass flows for the year 2013 through a complex network of transformation processes, and by taking account of

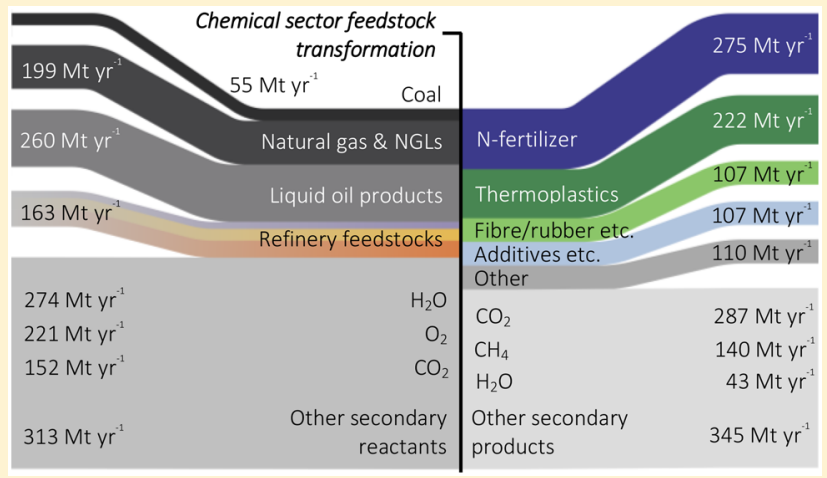
secondary reactants and by-products, we maintain a full mass balance throughout. The resulting data set partially addresses the dearth of publicly available information on the chemical sector's supply chain, and can be used to prioritise downstream mitigation options.
\end{abstract}

\section{INTRODUCTION}

Industrial chemicals and their derivatives pervade modern society. Although often diffuse in their application (e.g., pharmaceuticals), the bulk outputs of the chemical and petrochemical sector, (also referred to here as "the chemical sector"), are deployed in huge volumes to make millions of tonnes per year $\left(\mathrm{Mt} \mathrm{yr}^{-1}\right)$ of chemical products, such as fertilizers and plastics. Our industrialized economy is dependent on chemicals.

In performing this pivotal role, the chemical sector exerts a large environmental burden. It is responsible for approximately $7 \%$ of global anthropogenic global greenhouse gas (GHG) emissions, and $5.5 \%$ when only counting $\mathrm{CO}_{2}$ emissions. ${ }^{1}$ The sector's final energy consumption is the largest among industrial sectors: $42.5 \mathrm{EJ}$ in 2014, of which $25 \mathrm{EJ}$ is feedstock energy. ${ }^{2}$ Other sources of emissions include those stemming directly from the chemical transformations mobilized in reactors (process emissions), and from energy conversion in the transformation sector (indirect emissions). In addition to these gaseous emissions, chemical products can spawn pernicious aqueous discharges. The oft-publicised problem of fertilizer runoff contributing to hypertrophication, ${ }^{3}$ and the more recent exposition of plastic waste ending up in the world's oceans $^{4,5}$ and organisms ${ }^{6}$ are notable examples.

This environmental strain magnifies as demand rises: the International Energy Agency (IEA) projects a 2.8-fold increase in demand for the sector's 18 most energy-intensive chemicals by $2050 .{ }^{1}$ The IEA also estimates that to maintain a "2DS" trajectory (in which there is a 50\% chance of limiting a global mean temperature rise to $2{ }^{\circ} \mathrm{C}$ above preindustrial levels), a $30 \%$ reduction in direct industrial $\mathrm{CO}_{2}$ emissions by 2050 is required, relative to 2014 levels. ${ }^{2, p .166}$ Without a disproportionate emissions reduction elsewhere, achieving a 30\% cut in absolute chemical sector emissions levels while sustaining a 2.8 fold increase in output means a $75 \%$ reduction in emissions per unit of production by 2050. This is a daunting task for a competitive industrial sector in which efficiency gains are already incentivised by exposure to fuel and feedstock price volatility.

1.1. Current Options for Reducing Feedstock Energy Consumption. Theoretical estimates made by Neelis et al. reveal the chemical sector's overall exothermicity, that is, if fully captured, the energy released in processing chemical feedstocks would be sufficient to supply all process energy requirements. ${ }^{7}$ This seems to be reflected by the increase of feedstock energy as a share of the sector's total energy input, from $44 \%$ in 1971 to $58 \%$ in 2013 . However, this could be because of changes to reporting regimes used to compile these statistics. A countervailing downward pressure on the share of feedstock energy is process yield improvement. However, this lever is constrained by stoichiometry, and in many cases process yields are close to

Received: September 5, 2017

Revised: January 11, 2018

Accepted: January 24, 2018

Published: January 24, 2018 
practical limits. This leaves only marginal improvement potential, which is difficult to realise. The quantity, and importance of feedstock energy is likely to continue to grow. In a recent edition of their Energy Outlook, BP seem to concur, stating that "non-combusted fuel use becomes the largest source of fossil fuel demand growth toward [2035]" (ref 8, p 17 ) in part because of "limited scope for efficiency gains"(ref 8 , p 27) in the petrochemical sector.

This prognosis is uncontroversial, and there is little disagreement around the prescriptions for mitigation. Broadly speaking, three main decarbonisation levers receive most attention: feedstock and fuel substitution (including biomass), ${ }^{9-14}$ process energy efficiency potential ${ }^{7,15-19}$ and innovative low carbon technologies ${ }^{1,20,21}$ (including Carbon Capture and Storage (CCS)). These prescriptions are all "upstream" measures, that is, closer to the supply side and the producer. "Downstream" mitigation options, that is, those closer to the demand-side and the consumer, receive comparatively little attention. Material efficiency strategies, whereby the same service is provided with less materialthereby reducing material demand-are a key group of downstream mitigation options. Allwood and Cullen ${ }^{22}$ explore several strategies for bulk materials, including light-weighting and process yield improvement, but even among the vanguard of global energy modeling efforts, sophisticated chemical sector analyses tend to be restricted to the recycling of certain plastics. $^{2,23-25}$

Pioneering material and end-use efficiency analyses relating to the chemical sector are not without incidence. Worrell et al., ${ }^{26}$ Hekkert et al. ${ }^{27}$ and Gielen ${ }^{28}$ examined some of the key sectors (fertilizer, plastic packaging) and strategies (efficient application, recycling) available downstream of the chemical sector. Scholarship in these areas has not evolved much since. The main reason for this is the complexity of the sector's supply chain, and the subsequent lack of publicly available material flow data. There is an urgent need for a mass-balanced and transparently compiled account of the sector's main material flows, so that reliable estimates of the impacts of downstream mitigation options can be made. Until this gap in the literature is addressed, these options will remain under-represented, relative to their potential in recommendations to policy makers.

1.2. Chemical Sector Data: Few and Far Too Costly. This work follows similar studies of the steel ${ }^{29}$ and aluminum ${ }^{30}$ industries, but the dearth of public data on the chemical sector has made it substantially more challenging. We posit three principal reasons for the inferior data landscape. First, the chemical sector is a complex multisector industry, despite its aggregated accounting entries in energy statistics. ${ }^{31,32}$ Its outputs are numerous and diverse, supplying a wide variety of material and energy services. Second, the International Council of Chemical Associations (ICCA), a trade association and "worldwide voice of the chemical industry", 33 falls short of its counterparts in the steel (World Steel Association) ${ }^{34}$ and aluminum (International Aluminum Institute) ${ }^{35}$ industries on data provision. These metal industry associations' data were pivotal to the steel and aluminum studies cited above. Some reliable subsets of data on the chemical sector have been identified, such as those from the International Fertilizer Association (IFA) ${ }^{36}$ and Plastics Europe, ${ }^{37}$ but these tend to be fragmented with respect to their sectoral and geographic coverage. Lastly, the comprehensive data that are collected on the sector are proprietary and highly commoditised. Such databases are generally not available for use in academic studies-including this one.

1.3. Components of Mapping in Previous Studies. For our stated purpose-establishing a firm basis on which to appraise downstream mitigation options-a sufficiently detailed, globally balanced and publicly available map of the chemical sector is required. No such map has been identified in the academic or gray literatures. However, several elements of chemical sector mapping have been conducted as components of previous studies for, broadly speaking, three purposes: examining the robustness of emissions and energy statistics; compiling emissions estimates associated with the non-energy use of fossil fuels; and to inform bottom-up energy modeling efforts for the sector. In this section, we highlight salient studies with a focus on the mapping work involved.

Bottom-up analyses of the main feedstock consuming processes in the chemical sector are employed to scrutinize top-down international energy statistics on non-energy use, such as an international study ${ }^{38}$ by Weiss et al. and a Dutch study $^{39}$ by Neelis and Pouwelse. Multiple reporting irregularities are identified, and each study indicates a need for increasing the quality of chemical sector energy statistics. Studies with similar findings stem from a broader energy efficiency analysis of European industry by Worrell et al. ${ }^{40}$ in the early 1990s, and are most recently echoed nearly two decades later by Saygin et al. ${ }^{41}$ in their analysis of the German chemical sector. These studies contain partial data on feedstock energy consumption, upstream chemicals production, installed capacity and feedstock requirements. With the exception of the latter, ${ }^{41}$ they focus on upstream chemical production, thereby providing little information on the majority of the sector's material flows. In all cases the mapping work is the means rather than the end, and is either undisclosed, insufficiently detailed or limited in scope.

Neelis et al. ${ }^{42}$ construct a NEAT (non-energy emissions accounting table) model to compile $\mathrm{CO}_{2}$ emission estimates associated with non-energy use flows, which is employed to compile national non-energy emissions inventories for the Republic of Korea, ${ }^{43}$ Italy, ${ }^{44}$ Germany ${ }^{45}$ and The Netherlands. ${ }^{46}$ By better describing the degree to which non-energy consuming products are oxidized during or after use, the model allows the authors to improve emissions inventories, relative to those compiled with the IPCC reference approach available at the time. ${ }^{4}$ The model requires production and trade data for 77 organic and 18 inorganic chemicals, which the authors acknowledge is an extensive data requirement. The countrylevel studies prove it is possible, but only with close cooperation from national statistical offices or consultancies. No intermediate mapping data are presented in the countrylevel studies.

The MATTER (MATerials Technologies for greenhouse gas Emission Reduction) project in the late 1990s may have represented the peak of ambition with regards to integrated energy- and materials-related climate change mitigation research. Kram et al. ${ }^{48}$ summarize the overall MATTER project findings: the inclusion of demand-side options (e.g., material efficiency and substitution) alongside supply side options (e.g., wind turbines and solar panels) hastens progress toward, and brings down the costs of emissions mitigation. Groenendaal and Gielen ${ }^{49}$ summarize a sector-specific study of the petrochemical sector. In a related project, Joosten ${ }^{50}$ examines plastic flows in The Netherlands using national supply and use statistics. Each provides a contemporary snapshot of aspects of 
the petrochemical industry, and some of the most detailed energy and materials maps of the industry identified in the literature. However, only western Europe is covered (where data are relatively plentiful and publicly available); some important feedstock-consuming chemicals such as ammonia are excluded, and the studies are nearly 30 years old.

Other elements of chemical sector mapping are identified in industrial energy ${ }^{51}$ and exergy ${ }^{52}$ efficiency studies; specific analyses of plastics flows; ${ }^{53}$ broader analyses of chemical sector energy consumption and emissions in the $\mathrm{UK}^{54}$ and globally; ${ }^{14,55,56}$ and in flowcharts published by trade associations. $^{57,58}$ However, among the existing information we have examined, no mapping component or selection thereof is sufficient to provide us with the framework we require. This is not a criticism of studies where this was not their purpose. The remainder of this study outlines the methodology (section 2) used to assemble the mapping results (section 3) required to fill this gap in the literature. In section 4, we use comparisons and a sensitivity analysis to critically examine our results.

\section{MATERIALS AND METHODS}

This section contains an overview of the methods used to construct a data set of global chemical sector mass flows. A snapshot of the Material Flow Analysis-based (MFA) data set is presented as a Sankey diagram, a complementary pairing of analytical tools for supply chain analyses. ${ }^{59-62}$ The full details of the data set are delineated in the Supporting Information (SI). After outlining the scope of the analysis, this section summarizes the upstream and downstream calculations sequentially.

2.1. Analysis Scope. The temporal (2013) and geographic (global) boundaries of this study are chosen to align with common reporting intervals for production statistics, and to negate the need to consider trade. 2013 is sufficiently recent to construct a contemporary picture of the industry, but not so recent as to limit data availability. Stocks of products within the supply chain boundary are assumed to be negligible, based on evidence for several chemicals where supply and demand information is available. ${ }^{63}$ Furthermore, many of the sector's products are gaseous and/or toxic, incurring significant expense when stored. "In-use" stocks are not considered in static analyses, but any subsequent dynamic analysis would need to take account of varying product lifetimes, especially for plastics.

Only virgin production routes and fossil fuel feedstocks are considered. Secondary production routes (those based on recyclate) and alternative feedstocks form a small fraction of overall inputs to the sector. Global demand for plastics-a subset of chemical products for which scalable secondary and bio-based routes exist-is currently estimated at $311 \mathrm{Mt} \mathrm{yr}^{-1}{ }^{37}$ Global inputs of plastic recyclate are of the order of $10 \mathrm{Mt} \mathrm{yr}^{-1}$, and total Bioplastic production capacity is approximately $1.7 \mathrm{Mt}$ $\mathrm{yr}^{-1}$. $51,64,65$

The European Chemicals Agency (ECHA) keeps an inventory of commercially manufactured chemicals. The entries currently number 106213 at the time of writing, ranging from fertilizer precursors produced on the $10^{11} \mathrm{~kg}$ scale, such as ammonia, to powerful analgesics administered in dosages on the $10^{-6} \mathrm{~kg}$ scale, such as fentanyl. ${ }^{66}$ Clearly a narrower focus is required. Just 18 chemicals account for $63 \%$ and $75 \%$ of the sector's process energy consumption and GHG emissions, respectively. ${ }^{1}$ Tracing these chemicals and their main derivatives downstream to chemical products results in the inclusion of 77 chemicals and 65 processes. We return to assess the degree of coverage achieved in section 4.

2.2. Mapping Upstream Chemical Production. The upstream portion of the data set maps inputs of fossil fuel feedstocks to the sector's largest-volume chemicals, the salient details of which are described under the headings below.

Ammonia and Methyl Alcohol. Although promising fossil fuel-free routes to ammonia and methyl alcohol are available via various types of electrolysis, ${ }^{67}$ the vast majority of global capacity is based on natural gas, oil product (naphtha, LPG etc.) and coal feedstocks. We apply estimates of feedstock input percentages ${ }^{68}$ to production figures ${ }^{36,69}$ to get tonnages of ammonia $\left(120.5,14.4\right.$, and $34.8 \mathrm{Mt} \mathrm{yr}^{-1}$ ) and methyl alcohol

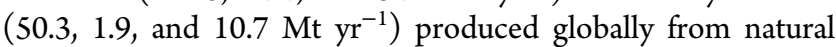
gas, oil and coal, respectively.

Generalized stoichiometric expressions are formulated to characterize the ammonia and methyl alcohol production processes, which each comprise synthesis gas (syngas) production and chemical synthesis steps. We assume the chemical synthesis steps are consistent irrespective of the feedstock used, but distinguish between steam methane reforming (SMR) and partial oxidation (POX) syngas units. The water gas shift and reverse water gas shift reactions, employed to obtain the appropriate $\mathrm{CO}: \mathrm{H}_{2}$ syngas ratios for each feedstock/product combination, are integrated within the syngas production characterisations. All terms in the generalized stoichiometric expressions can be described precisely with chemical notation $\left(\mathrm{NH}_{3}, \mathrm{CO}_{2}\right.$ etc.), apart from the feedstock inputs, which are non-uniform combinations of carbon/ hydrogen $(\mathrm{C} / \mathrm{H})$, and some non- $\mathrm{C} / \mathrm{H}$ content. Generalized characterisations in the form $\mathrm{CH}_{n}$ are used, where " $n$ " determines the average carbon-to-hydrogen ratio of the feedstock's constituent molecules. Appl ${ }^{70}$ and Rainer et al. ${ }^{71}$ provide feed and product profiles for several real-world syngas plants. From multiple plants' feed data, typical values of $n$ for natural gas, oil and coal feeds of 3.951, 1.873, and 0.456 were calculated. The terms are then combined and balanced, resulting in the full stoichiometric expressions for each product and process route.

The mass proportions of the terms in the balanced stoichiometric expressions, along with the global production estimates above, are used to calculate corresponding quantities of feedstocks, secondary reactants and secondary products. Aggregated loss terms are incorporated to account for imperfect conversion and selectivity at the syngas and chemical synthesis steps, and any non- $\mathrm{C} / \mathrm{H}$ content transiting the process. Typical syngas conversion efficiencies-the higher heating value (HHV) of the $\mathrm{CO} / \mathrm{H}_{2}$ product relative to that of the feedstock inputwere computed using average $\mathrm{HHV}$ values for each fuel ${ }^{72}$ and the syngas profile data: ${ }^{70,71} 86.1 \%$ for natural gas (SMR), $80.8 \%$ for oil (POX) and $76.0 \%$ for coal (POX). There are also small losses at the synthesis steps, described by the chemical yield: $98.0 \%$ for ammonia $^{73}$ and $99.0 \%$ for methyl alcohol syntheses. $^{74}$ These calculation steps result in a global massbalance for ammonia and methyl alcohol production. For more information, see section 4 of the SI.

Steam Cracking. Capacity (in $\mathrm{Mt} \mathrm{yr}^{-1}$ of ethylene) and feed (in percentages of ethane, naphtha etc.) data for 277 steam crackers were taken from the Oil \& Gas Journal's annual surveys. $^{75,76}$ Estimates were made for omitted data, using adjacent countries' or regions' figures. Typical yield profiles for steam crackers run on various feeds are provided by the 
European Commission. ${ }^{77}$ The following identity describes the relationship between theses quantities:

$$
F_{t} \cdot\left[\begin{array}{lllll}
y_{a, 1} & y_{a, 2} & y_{a, 3} & \cdots & y_{a, n} \\
y_{b, 1} & y_{b, 2} & y_{b, 3} & \cdots & y_{b, n} \\
y_{c, 1} & y_{c, 2} & y_{c, 3} & \cdots & y_{c, n} \\
\vdots & \vdots & \vdots & \ddots & \vdots \\
y_{i, 1} & y_{i, 2} & y_{i, 3} & \cdots & y_{i, n}
\end{array}\right] \cdot\left[\begin{array}{c}
f_{1} \\
f_{2} \\
f_{3} \\
\vdots \\
f_{n}
\end{array}\right]=\left[\begin{array}{c}
P_{a} \\
P_{b} \\
P_{c} \\
\vdots \\
P_{i}
\end{array}\right]
$$

Where $F_{\mathrm{t}}$ is the total quantity of all feeds in ${\mathrm{Mt} \mathrm{yr}^{-1}, P_{\mathrm{a}-\mathrm{i}} \text { are }}$

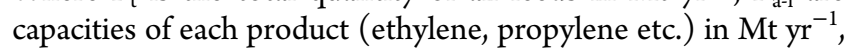
$y_{i, n}$ is the yield of product " $i$ " from a unit of feed " $n$ " and $f_{1-n}$ are the fractions each feed forms of $F_{\mathrm{t}}$.

The results of using [1], first by solving for $F_{\mathrm{t}}$ using one known production quantity (say $P_{\mathrm{a}}$ ), and then using $F_{\mathrm{t}}$ to compute the quantities of the remaining products $P_{\mathrm{b}-\mathrm{j}}$, are in capacity rather than production terms. An average utilization rate was estimated using global ethylene production data published by the Japanese government, ${ }^{63}$ and applied to the capacitybased profile to obtain production quantities. For more information, see section 5 of the SI.

BTX Aromatics and C4 Olefins. C4 olefins are coproduced alongside ethylene and propylene in steam crackers run on both light (e.g., ethane) and heavy (e.g., naphtha) feeds, as opposed to the BTX (benzene, toluene, and xylene) aromatics, which are only produced when cracking heavier feedstocks. The remaining quantities of BTX aromatics and C4 olefins produced globally are mainly recovered from various refining processes' raffinate and pyrolysis gasoline streams, such as those from fluid catalytic crackers and catalytic reformers. Bender ${ }^{78,79}$ provides recent global average estimates of the proportions of C4 olefins and BTX aromatics obtained from each of these sources.

BTX aromatics streams often undergo further transformation after extraction. Principal among these transformations is the conversion of toluene to xylene and benzene, via hydrodealkylation and disproportionation. Burdick and Leffler ${ }^{80}$ provide typical feed and product profiles for each process. For more information, see sections 6-7 of the SI.

On-Purpose Technologies. Multiproduct processes, such as steam cracking, may not yield products in a ratio equal to that of their demands. On-purpose technologies can help address such an imbalance, by producing products in a complementary ratio, or one at a time. Three on-purpose technologies are characterized in this mapping work: propane dehydrogenation (PDH), metathesis (MTS), and methanol-to-olefins (MTO). These flexibility-enhancing technologies' capacities are relatively small (<11 $\mathrm{Mt} \mathrm{yr}^{-1}$ of capacity combined, although growing rapidly in certain regions), so uniform characterisations are used for each. Various sources are used to compile feed and product profiles for each of these technologies, which are delineated in section 8 of the SI.

Carbon Black. Carbon black is an important chemical ingredient for the production of tires and pigments. We estimate global mass flows associated with carbon black production by characterizing two technologies: the furnace black (partial oxidation) and thermal black (thermal cracking) processes. Information from the European Commission ${ }^{81}$ suggests the thermal black process is used exclusively to produce specialty blacks and that the dominant furnace black process is used mostly to produce reinforcing blacks, along with the remainder of specialty black production. There are several other small volume process routes for the production of carbon black (e.g., acetylene black), but these are negligible in global terms and are therefore omitted for simplicity. Section 9 in the SI contains the global feed and product profile for carbon black.

2.3. Mapping Downstream Chemical Production. The downstream portion of the data set maps the upstream chemical products through three tiers of downstream processes to chemical products - the downstream boundary of the analysis. The calculations involved are repetitive, so an overview of the general methodology is provided rather than a description for each process. Sections $10-15$ of the SI contain full details of both the primary and secondary downstream flow calculations. Whether a flow is primary, secondary, a reactant, or a product depends on the process to which they relate. As an example, in the urea production process, urea is the primary product and ammonia the primary reactant, with carbon dioxide and water being the secondary reactant and product, respectively.

Primary Reactant and Product Quantities. Primary reactant quantities are computed by multiplying the primary product quantities by industrially representative input requirements (see sections $12-13$ in the SI). The difference between the total production volume of a given chemical, and the sum of quantities of that chemical allocated to downstream processes or specific chemical product categories forms a residual, which is directed to the "Other" product category. Section 14 in the SI fully delineates the calculation steps and data sources associated with the primary reactant and product quantities.

Process Characterisations. Stoichiometric process characterisations are compiled for all 55 downstream processes. In each case, a single reaction equation is formed either directly, or by combining several component reaction steps. With few exceptions, only the dominant production technology for a given downstream chemical is represented in the process characterization, to avoid prohibitive complexity. This "onetechnology" approach represents a compromise for some downstream processes. However, technology variants are often structurally identical in material flow terms, but utilize alternative catalysts or process arrangements. In these instances, the compromise adopted will have limited impact on the mass flows calculated in the context of this high-level, global analysis. See sections 10-11 in the SI for detailed derivations and a table summarizing all the characterisations used.

Secondary Reactant and Product Quantities. Secondary flows facilitate a mass balance for each process. As per the relevant step in the ammonia and methyl alcohol methodology (see section 2.2), the mass proportions stipulated in the process characterisations are used to calculate the quantities of all downstream secondary reactant and product flows. For each process, this is done in three steps. First, the secondary reactant quantities are calculated by scaling the primary input quantity according to the mass ratio of the primary input and secondary reactant terms in the process characterization. Second, the quantities of secondary products in the process characterization are calculated, by scaling the primary input quantity according to the mass ratio of the primary input and secondary product terms. The final step is to balance the process with a subset of secondary products, those resulting from an imperfect reaction yield. This is done by subtracting the output quantities already calculated (primary and secondary) from the input quantities. This secondary product subset can consist of any unreacted inputs, other undefined products resulting from side-reactions, 


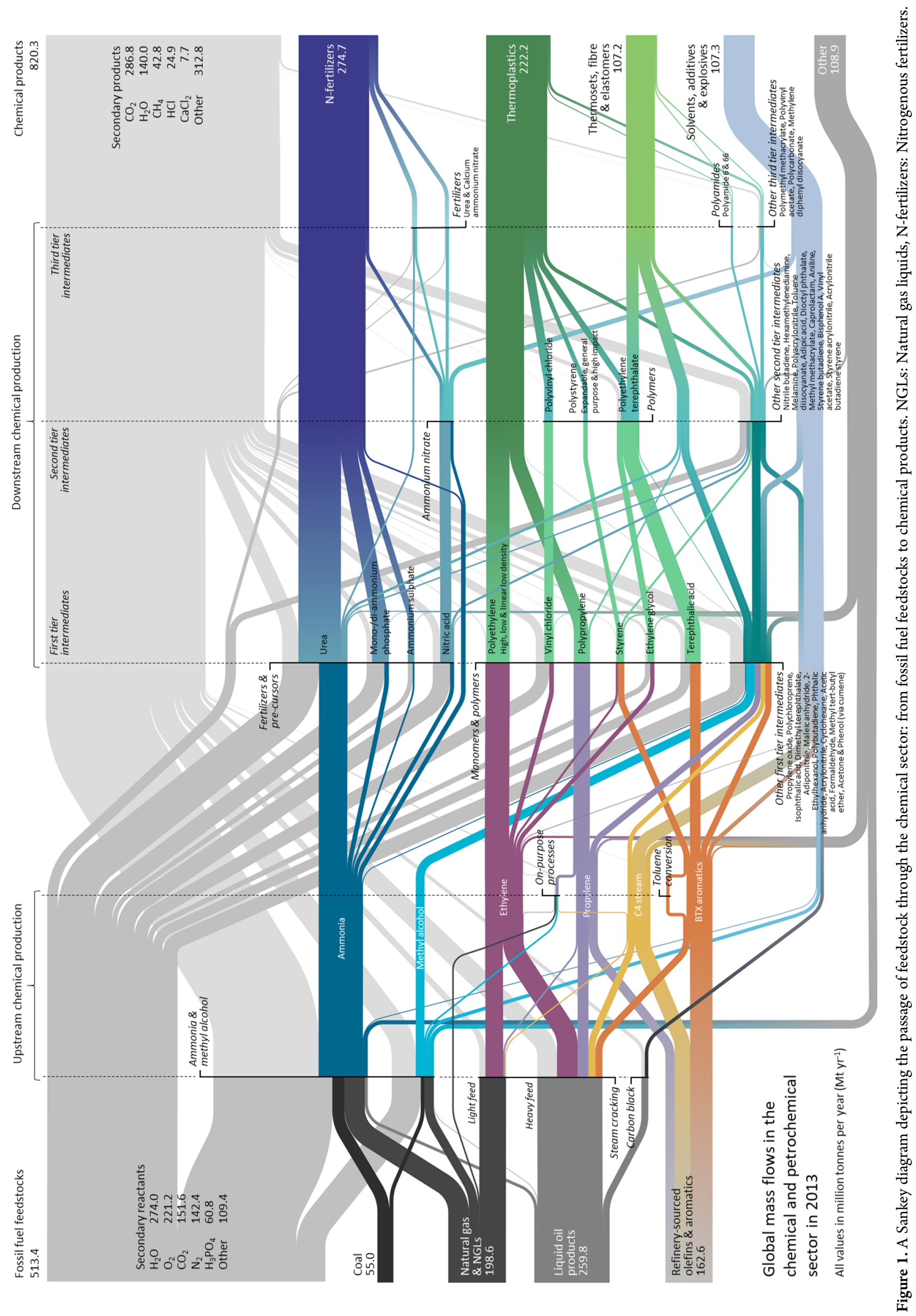


or a combination thereof. See section 15 in the SI for a detailed explanation of these calculations.

2.4. Sensitivity Analysis. A one-at-a-time sensitivity analysis is used to identify the most influential parameters in our data set. This involved sequentially imposing an arbitrary $10 \%$ variation on individual mass flows' magnitudes, while monitoring the consequent impact on total feedstock input to the chemical sector. This direct variation of flow quantities has the same impact as indirectly varying the underlying yield and production parameters, but facilitates faster computation. The sensitivity is measured by a single value, by converting the tonnages of feedstocks - each with non-uniform lower heating values (LHV) - to energy content. ${ }^{72}$ For upstream multi-input/ multi-output processes, such as steam cracking, the tonnages of inputs to these processes are allocated evenly across the total tonnage of primary products. This methodology necessarily differs from allocation practices adopted in energy benchmarking contexts, where energy inputs are allocated across only a selection of products (e.g., Solomon Associates' Olefin Study). ${ }^{82}$ In a sensitivity context, it would make little sense for variations in one of several of a process's products to have no, or less impact, relative to another.

\section{RESULTS}

Figure 1 depicts our best assessment of global mass flow in the chemical sector in 2013, corresponding to the analysis scope outlined in section 2.1. The results are displayed in a Sankey diagram, which maps $513.4 \mathrm{Mt} \mathrm{yr}^{-1}$ of fossil fuel feedstocks and 162.6 $\mathrm{Mt} \mathrm{yr}^{-1}$ of refinery feedstocks, through to $820.3 \mathrm{Mt} \mathrm{yr}^{-1}$ of chemical products. This apparent imbalance of inputs and

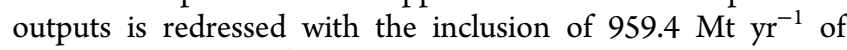
secondary reactants (gray flows entering the diagram in the top left) and $815.0 \mathrm{Mt} \mathrm{yr}^{-1}$ of secondary products (light gray flows exiting the diagram in the top-right) stipulated by the stoichiometry in the characteristic process equations (see section 11 of the SI). The inclusion of secondary products and reactants means that a mass balance is achieved at any vertical section in the diagram.

There is no standard diagrammatic structure for the chemical sector. The structure adopted in Figure 1 was devised with the aim of providing a comprehensive overview of the significant mass flows in the chemical sector, while balancing complexity and clarity. The horizontal ordering of processes is formed according to the sequence of transformation. The vertical ordering is formed by clustering similar chemical products' production processes together (e.g., Polymers). Color is used among the primary product flows to distinguish subsector supply chains (e.g., shades of blue for nitrogenous (N-) fertilizers, and shades of green for various polymers), although the intertwined nature of the sector's supply chain makes continuous distinction impossible.

There is a varying level of process aggregation at each junction in the diagram. In certain cases, only material flows entering and exiting a single production process are displayed (e.g., Urea production). In others, the material flows associated with several processes for producing a single product are aggregated (e.g., Ammonia production, comprising coal, oil, and natural gas routes). At the more complex downstream nodes, the material flows pertaining to multiple products are aggregated (for example, the Intermediates (1) node depicts the material flows associated with the production of 16 primary products; annotations accompany these multiproduct aggregations). This varying level of process aggregation is employed to achieve visual clarity, but can be disaggregated and rearranged using the descriptions of all flow components in sections 14-15 of the SI. A digital version of the mapping framework might allow the user to vary the granularity of the data set in real time.

\section{DISCUSSION}

Our results comprise a hitherto unavailable picture of the global chemical sector supply chain, based entirely on public data. It reveals the sector's structure, its important mass flows, their origins and destinations. Of the sector's $513.4 \mathrm{Mt} \mathrm{yr}^{-1}$ of fossil fuel feedstock input, $24 \%$ is consumed in ammonia production, $9 \%$ for methyl alcohol, $5 \%$ for carbon black and $62 \%$ is fed to steam crackers - the latter portion split approximately in a 1:2 ratio between light and heavy feed units. In addition to the cracker-sourced olefins and aromatics (approximately 57\%), approximately $40 \%$ are sourced directly from the refining sector and less than $3 \%$ from three much-lauded, but globally marginal on-purpose processes. Among the downstream production processes, of the 25 first-tier intermediate transformations modeled, just 10 dominate upstream chemical consumption, with a further 15 accounting for just $22 \%$. Polyethylene terephthalate (fiber and resin) and ammonium nitrate production consume $52 \%$ of the chemical inputs to 22 second tier intermediate transformations. No such consolidation is present at the third tier. Nitrogenous $(\mathrm{N}-)$ fertilizers and thermoplastics together account for just over $60 \%$ of the sector's chemical products, thereby constituting important, but by no means the exclusive, demand drivers for the sector.

In the absence of any robust basis on which to quantify the uncertainty in our source data-no error bounds or confidence intervals accompany the production and yield data used-it is impossible to perform a meaningful uncertainty analysis. However, four steps are taken to mitigate the impacts of uncertainty in our source data on the overall picture conveyed. First, the varying levels of precision present in our source data are universally curtailed, with all tonnages rounded to the

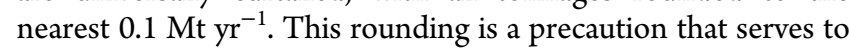
increase the robustness of our numeric results. Second, we make two sets of comparisons between our results and those from other studies (section 4.1); one at either end of the supply chain. Third, focusing on N-fertilizers and thermoplastics, we discuss the results of a sensitivity analysis (section 4.2; method described in section 2.4) to examine the relative importance of various parameters. Finally, comprehensive and transparent SI is provided, which details all assumptions and data sources. We conclude the paper with some suggestions for future work, and a final word on the pressing need to improve chemical sector data availability (section 4.3).

4.1. Comparison of Results. This section contains two comparisons. First, the estimates of feedstock inputs entering the sector on the upstream side of Figure 1 are compared with top down energy statistics from the IEA. ${ }^{31}$ Second, the chemical product quantities on the downstream side of Figure 1 are compared with tangential estimates made in other studies. ${ }^{51,56}$ Full details of the steps involved in the comparisons are provided in section 17 of the SI.

Upstream Comparison. The IEA's World Energy Balances database $^{31}$ is a potentially useful mine of data on the chemical sector's feedstock inputs. A subcategory of industrial nonenergy use, the "of which: Chem./Petrochem." line contains quantities of each energy product consumed as feedstock in the chemical sector. This line in the energy ledger should be compiled on a net basis, thereby excluding any feedstock that 
gets used to fuel chemical processes. The global totals in the balance should therefore be comparable with the mass quantities on the left-hand side of Figure 1, once converted to energy content, on a LHV basis.

Weiss et al. ${ }^{38}$ found the IEA data to be relatively robust at the global level, so we emulate their comparative approach to examine the feedstock quantities in our analysis. We use global data from the same IEA database, and energy quantities derived from the mass quantities and LHVs of the inputs on the lefthand side of Figure 1. We exclude the quantities of olefins and aromatics sourced from the refining sector, as these should not be recorded in this line of the balance. We also sharpen the resolution of the comparison by looking at specific energy products (where directly comparable categories were available). Table 1 summarizes the data used in the comparison.

Table 1. Upstream Comparison Results

$\begin{array}{lcc}\text { feedstock } & \text { this study, } 2013\left(\mathrm{EJ} \mathrm{yr}^{-1}\right) & \mathrm{IEA}, 2013\left(\mathrm{EJ} \mathrm{yr}^{-1}\right) \\ \text { coal } & 1.5 & 0.1 \\ \text { ethane } & 2.6 & 2.5 \\ \text { gas oil } & 1.0 & 0.3 \\ \text { natural gas } & 5.1 & 6.8 \\ \text { naphtha } & 9.2 & 10.0 \\ \text { other } & 3.5 & 4.3 \\ \text { total } & 22.7 & 24.1 \\ \end{array}$

At the aggregated level of the Weiss et al. analysis (see the bottom row of Table 1), the figures compare well. The IEA figure of $24.1 \mathrm{EJ}$ is only 6\% greater than our bottom-up figure; a discrepancy which could be mostly explained by quantities of feedstock consumed for small volume products outside the boundary of our analysis (e.g., acetylene production), or the erroneous inclusion of some refinery-sourced products. However, comparisons at the individual energy product level tell a more nuanced story.

There are five energy product categories in the IEA extended energy balance which should be unambiguously comparable with sub-groups of our data. For three of these (coal, ethane and gas oil) our results suggest there is under-reporting in the IEA data. For coal, the discrepancy is more than an order of magnitude, which is likely due to reporting omissions of coal feedstock energy consumption in ammonia, methyl alcohol and MTO facilities. The predominant consumer of coal for chemical feedstock is China. For the other two directly comparable product categories (natural gas and naphtha) there seems to be over-reporting. In line with Weiss et al., we assume these discrepancies stem in large part from varying determinations of feedstock energy consumption, such as the erroneous inclusion of fuel inputs. This assumption is reinforced by the large discrepancy for natural gas, because feedstock and fuel inputs in natural gas-fed ammonia and methyl alcohol plants are closely entangled and often identical in composition.

Downstream Comparison. Several studies make estimates of the bulk outputs of the chemical sector, to appraise the potential for efficiency improvement or recycling potentials. Here we compare our results with estimates from two such studies. $^{51,56}$

Gielen et al. provide a mass balance of the global petrochemical sector (i.e., excluding fertilizer and other inorganics) for 2004. ${ }^{51}$ No direct comparisons can be made between absolute figures, because of the differing reference years and scopes of the analyses. However, the proportions each product group forms of the sector's total output in each analysis can be compared. A flowchart in the paper suggests that plastics, fiber and synthetic rubber account for $82 \%, 14 \%$, and $4 \%$ of total sector output, respectively. By regrouping the data constituting the downstream side of Figure 1, we get $81 \%, 16 \%$, and $3 \%$ for the same product groups. The close alignment between these shares is encouraging, as one would not expect large structural changes in the sector at this highly aggregated level in the nine years between the analyses' reference years. Furthermore, the apparent growth segment, fiber, is one that has seen sector-leading growth rates for its large volume products, especially polyester. $^{83}$

A similar set of downstream data is available for the plastics segment specifically, in an IEA industry-wide analysis. ${ }^{56}$ A figure showing the end-uses of plastics shows global 2006 production tonnages for 13 thermoplastic categories. Again, using the relative shares rather than absolute values, a rough comparison can be made between the total plastic production quantities in the IEA's figures, and those obtained in our analysis. Five of the 13 categories' shares match exactly, to the nearest percentage point. A further six differ by one percentage point, and the biggest difference is polyvinyl chloride, for which the IEA share is $14 \%$ and our analysis suggests $11 \%$. This comparison is also favorable, and the variations are within plausible bounds of the restructuring of plastics' market shares over the seven intervening years between analyses.

4.2. Sensitivity Analysis Results. Potential sources of inaccuracy in our results are erroneous or approximated yield and production data, and an insufficiently detailed level of sector coverage. In this section we examine the potential impact of such inaccuracies using the results of a sensitivity analysis (method described in section 2.4).

The left-hand graph in Figure 2 displays the results for the 10 most sensitive flows based on a $10 \%$ variation in their original

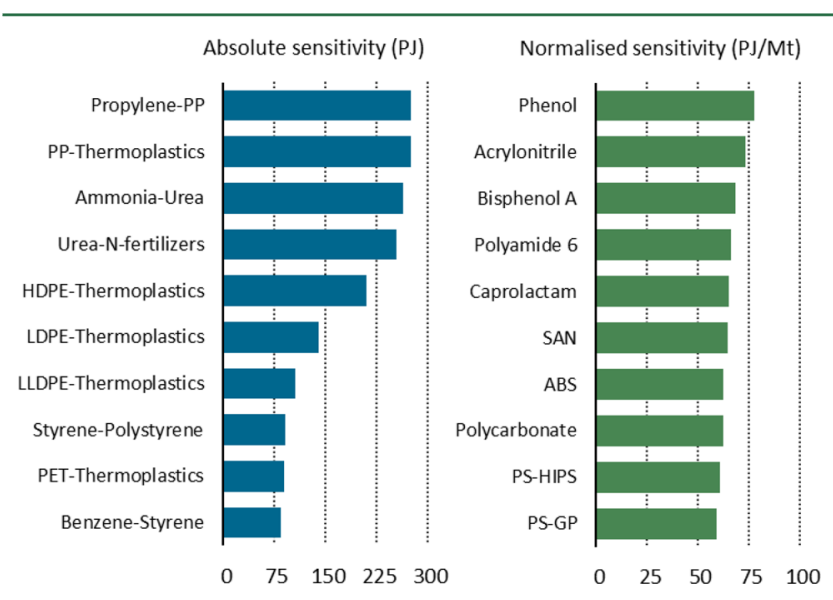

Figure 2. The ten most sensitive flows on an absolute (LHS) and normalized (RHS) basis among the $\mathrm{N}$-fertilizer and thermoplastics supply chains. PP: Polypropylene, HDPE/LDPE/LLDPE: High, low, and linear low density polyethylene, PET: Polyethylene terephthalate, PS-HIPS/PS-GP: High impact and general purpose polystyrene, SAN: Styrene acrylonitrile, ABS: Acrylonitrile butadiene styrene.

magnitude. The most important flows by this measure are those that have a large original magnitude. For example, a 10\% (5.1 $\mathrm{Mt}$ ) reduction in the quantity of propylene used to make polypropylene yields $276 \mathrm{PJ}$ of feedstock energy savingsapproximately equivalent to the annual electricity consumption 
of Finland. This list emphasizes those flows where inaccuracies in their underlying parameters will have an impact proportional to their size, for example, the inaccuracy in a reported yield. Flows that merely constitute a sum of downstream flows (for instance polyethylene, which groups three polyethylene resins) have been omitted from this list, as this would suppress their underlying component flows' down the ranking, thereby obscuring their importance. The right-hand graph of Figure 2 shows results that are normalized for the original flow magnitude, that is, the analysis results for the left-hand graph divided by the magnitudes of their variations. This list emphasizes flows that have the largest feedstock energy "footprint", which tend to be those that involve multiple and/or low-yield transformations. Inaccuracies in the parameters associated with these flows will have a relatively larger impact per absolute unit of variation. Section 18 of the SI contains the full set of sensitivity results for the $\mathrm{N}$-fertilizer and thermoplastic supply chains.

The sensitivity results help identify the analysis parameters that are deserving of further scrutiny. The sensitivity analysis also provides an initial insight into which components of the $\mathrm{N}$ fertilizers and thermoplastics supply chains are the most attractive targets for material efficiency interventions, from a feedstock energy consumption standpoint. The current arbitrary $10 \%$ variations imposed in the sensitivity analysis could represent a $10 \%$ material saving resulting from a specific material efficiency intervention. However, further analysisincluding combining the current data set with others on process energy intensities-would be required to characterize what savings are available for each product and intervention, and at what cost.

4.3. Future Work. We believe this analysis constitutes an important step toward facilitating the concurrent consideration of downstream mitigation options (material efficiency strategies) alongside traditional upstream options (process energy efficiency, CCS etc.) in the global chemical sector. There are three priority areas on which to focus future analytical effort:

- First, the temporal, technological and geographical resolution of this analysis must be extended, so that (a) temporal trends and disparities in the chemical sector may be more readily identified, (b) a higher resolution view of certain process variation may be obtained (e.g., a process variant for producing the same product with a different catalyst), and (c) the impacts of supply chain dynamics, such as material stocks, may be explored. Higher geographical resolution would also allow the assessment of circularity and industrial symbiosis potential in the chemical sector, by examining for example, the practical utilization of by-products from one process as reactants for another. An extension of the study to other largely unmapped sectors (such as refining) has the potential to examine even higher levels of integration.

- Second, an up to date, global portfolio of downstream mitigation options needs to be compiled, including their associated technical potentials and economic parameters. This would enable the modeling of impacts from varying efficiencies in material service provision, such as fertilizer application efficiency, or packaging-to-product weight ratios-a key blind spot in the current policy landscape downstream of the chemical industry.

- Third, the relevant aspects of this, and other supply chain analyses, need to become fully embedded within integrated assessment model frameworks, as per the early ambition of the MATTER model. ${ }^{48,49}$ Only then can the short shrift given to downstream mitigation options, relative to their upstream, technology-focused counterparts, begin to be redressed.

To achieve any of this efficiently, another problem must first be remedied. This study constitutes the most comprehensive and transparent data set of global chemical sector mass flows, available in the public domain. One would only need to provide a modest data set to affirm this seemingly bold claim, because of the lamentably poor data landscape of the chemical sector. It is difficult to identify a larger share of final energy consumption (the chemical sector accounts for roughly a tenth, globally) on which public data are so deficient.

This issue has been identified repeatedly over the past two decades, yet it remains a laborious task to compile even the most basic information on chemicals production. The situation is not much better in other bulk material sectors; let alone some of those likely to be integral to any low-carbon future (lithium, cobalt etc.). This study makes an important contribution to illuminating the chemical sector's global supply chain, but there is no F5 button to expediently refresh its underlying data set. Therein lies both the source of its novelty as an academic exercise, and its limited shelf life as a robust analytical tool. Considerable effort has been employed to compile comprehensive, accessible and transparent SI, composed based on publicly available data. This accompaniment should ease the burden of replicating and updating the data set in future. But without more and better materials data, analyses like this risk being a "one-off", or worse, relied upon beyond their expiry date.

\section{ASSOCIATED CONTENT}

\section{Supporting Information}

The Supporting Information is available free of charge on the ACS Publications website at DOI: 10.1021/acs.est.7b04573.

Detailed descriptions of the calculations, assumptions and sources used to compile the data underlying this study are available in an accompanying Supporting Information (SI) document consisting of 45 pages, 30 tables and 4 figures (PDF)

\section{AUTHOR INFORMATION}

\section{Corresponding Author}

*Phone: +44 (0) 1223 760360; e-mail: pgl26@cam.ac.uk; . ORCID ${ }^{\circ}$

Peter G. Levi: 0000-0002-0710-1715

Notes

The authors declare no competing financial interest.

\section{ACKNOWLEDGMENTS}

We thank the five anonymous reviewers and the journal editor. Their comments made for a much-improved article. This work was funded by a grant to the University of Cambridge from BP as part of their Energy Sustainability Challenge.

\section{REFERENCES}

(1) IEA; ICCA; Dechema. Technology Roadmap: Energy and GHG Reductions in the Chemical Industry via Catalytic Processes; OECD/IEA: Paris, 2013.

(2) IEA. Energy Technology Perspectives 2017. Catalysing Energy Technology Transformations; IEA/OECD: Paris, 2017. 
(3) Schindler, D.; Vallentyne, J. The Algal Bowl: Overfertilization of the World's Freshwaters and Estuaries. Can. Field-Naturalist 2008, 123, 188.

(4) Jambeck, J. R.; Geyer, R.; Wilcox, C.; Siegler, T. R.; Perryman, M.; Andrady, A.; Narayan, R.; Law, K. L. Plastic waste inputs from land into the ocean. Science (Washington, DC, U. S.) 2015, 347 (6223), $768-771$.

(5) The Ellen MacArthur Foundation. The New Plastics Economy: Rethinking the Future of Plastics, 2016.

(6) Van Cauwenberghe, L.; Janssen, C. R. Microplastics in bivalves cultured for human consumption. Environ. Pollut. 2014, 193, 65-70.

(7) Neelis, M.; Patel, M.; Blok, K.; Haije, W.; Bach, P. Approximation of theoretical energy-saving potentials for the petrochemical industry using energy balances for 68 key processes. Energy 2007, 32 (7), 1104-1123.

(8) BP. BP Energy Outlook: 2017 ed.; BP p.l.c.: London, 2017.

(9) Saygin, D.; Gielen, D. J.; Draeck, M.; Worrell, E.; Patel, M. K. Assessment of the technical and economic potentials of biomass use for the production of steam, chemicals and polymers. Renewable Sustainable Energy Rev. 2014, 40, 1153-1167.

(10) Gielen, D. J.; de Feber, M. A. P. C.; Bos, A. J. M.; Gerlagh, T. Biomass for energy or materials? Energy Policy 2001, 29 (4), 291-302.

(11) Gerssen-Gondelach, S. J.; Saygin, D.; Wicke, B.; Patel, M. K.; Faaij, A. P. C. Competing uses of biomass: Assessment and comparison of the performance of bio-based heat, power, fuels and materials. Renewable Sustainable Energy Rev. 2014, 40, 964-998.

(12) Zhu, Y.; Romain, C.; Williams, C. K. Sustainable polymers from renewable resources. Nature 2016, 540 (7633), 354-362.

(13) OECD. Biobased Chemicals and Bioplastics: Finding the Right Policy Balance; OECD Sceience, Technol. Ind. Policy Pap. 2014, No. 17.

(14) Daioglou, V.; Faaij, A. P. C.; Saygin, D.; Patel, M. K.; Wicke, B.; van Vuuren, D. P. Energy demand and emissions of the non-energy sector. Energy Environ. Energy Environ. Sci. 2014, 7, 482-498.

(15) Broeren, M. L. M.; Saygin, D.; Patel, M. K. Forecasting global developments in the basic chemical industry for environmental policy analysis. Energy Policy 2014, 64, 273-287.

(16) Saygin, D.; Worrell, E.; Patel, M. K.; Gielen, D. J. Benchmarking the energy use of energy-intensive industries in industrialized and in developing countries. Energy 2011, 36 (11), 6661-6673.

(17) Ren, T.; Patel, M.; Blok, K. Olefins from conventional and heavy feedstocks: Energy use in steam cracking and alternative processes. Energy 2006, 31 (4), 425-451.

(18) Ren, T.; Patel, M. K.; Blok, K. Steam cracking and methane to olefins: Energy use, $\mathrm{CO} 2$ emissions and production costs. Energy 2008, 33 (5), 817-833.

(19) Saygin, D.; Patel, M. K.; Worrell, E.; Tam, C.; Gielen, D. J. Potential of best practice technology to improve energy efficiency in the global chemical and petrochemical sector. Energy 2011, 36 (9), 5779-5790.

(20) IEA; UNIDO. Technology Roadmap Carbon Capture and Storage in Industrial Applications, 2011.

(21) Benner, J.; Lieshout, M. van; Croezen, H. Identifying Breakthrough Technologies for the Production of Basic Chemicals: A Long Term View on the Sustainable Production of Ammonia, Olefins and Aromatics in the European Region, 2012.

(22) Allwood, J. M.; Cullen, J. M. Sustainable Materials - With Both Eyes Open; UIT Cambridge: Cambridge, UK, 2012.

(23) IEA. World Energy Outlook 2015; OECD/IEA: Paris, 2015.

(24) IEA. Energy Technology Perspectives 2006: Scenarios \& Stragegies to 2050; IEA/OECD: Paris, 2006.

(25) IEA. Energy Technology Perspectives 2008: Scenarios and Strategies to 2050 ; 2008

(26) Worrell, E.; Meuleman, B.; Blok, K. Energy savings by efficient application of fertilizer. Resour. Conserv. Recycl. 1995, 13 (3-4), 233250.

(27) Hekkert, M. P.; Joosten, L. A. .; Worrell, E.; Turkenburg, W. C. Reduction of $\mathrm{CO} 2$ emissions by improved management of material and product use: the case of primary packaging. Resour. Conserv. Recycl. 2000, 29 (1), 33-64.

(28) Gielen, D. Materialising dematerialisation; Integrated energy and materials systems engineering for greenhouse gas emission mitigation. PhD Thesis, Design for Sustainability Program, 1999, 287.

(29) Cullen, J. M.; Allwood, J. M.; Bambach, M. D. Mapping the Global Flow of Steel: From Steelmaking to End-Use Goods. Environ. Sci. Technol. 2012, 46, 13048-13055.

(30) Cullen, J. M.; Allwood, J. M. Mapping the Global Flow of Aluminium: from Liquid Aluminium to Fabricated Goods: Supplemental Information. Environ. Sci. Technol. 2013, 47, 1-17.

(31) IEA. World Energy Balances 2016 ed.; OECD/IEA: Paris, 2016.

(32) IEA. Annual fuel questionnaires http://www.iea.org/statistics/ resources/questionnaires/annual/ (accessed January 30, 2017).

(33) ICCA. "The International Council of Chemical Associations (ICCA) is the Worldwide Voice of the Chemical Industry." https:// www.icca-chem.org/ (accessed January 30, 2017).

(34) World Steel Association. Steel Statistical Yearbook https:// www.worldsteel.org/steel-by-topic/statistics/steel-statistical-yearbook-. html (accessed January 30, 2017).

(35) IAI. World Aluminium; Statistics; Primary Aluminium Production http://www.world-aluminium.org/statistics/ (accessed January 30, 2017).

(36) IFA. Production and international trades statistics http://www. fertilizer.org//En/Statistics/PIT_Excel_Files.aspx (accessed January 30, 2017).

(37) PlasticsEurope. Plastics - The Facts 2015 - An Analysis of European Plastics Production, Demand and Waste Data; Association of Plastics Manufacturers: Brussels, 2015.

(38) Weiss, M.; Neelis, M. L.; Zuidberg, M. C.; Patel, M. K. Applying bottom-up analysis to identify the system boundaries of non-energy use data in international energy statistics. Energy 2008, 33 (11), 16091622.

(39) Neelis, M. L.; Pouwelse, J. W. Towards consistent and reliable Dutch and international energy statistics for the chemical industry. Energy Policy 2008, 36 (7), 2719-2733.

(40) Worrell, E.; Cuelenaere, R. F. A.; Blok, K.; Turkenburg, W. C. Energy consumption by industrial processes in the European Union. Energy 1994, 19 (11), 1113-1129.

(41) Saygin, D.; Worrell, E.; Tam, C.; Trudeau, N.; Gielen, D. J.; Weiss, M.; Patel, M. K. Long-term energy efficiency analysis requires solid energy statistics: The case of the German basic chemical industry. Energy 2012, 44 (1), 1094-1106.

(42) Neelis, M.; Patel, M. K.; Gielen, D. J.; Blok, K. Modelling CO2 emissions from non-energy use with the non-energy use emission accounting tables (NEAT) model. Resour. Conserv. Recycl. 2005, 45 (3), 226-250.

(43) Park, H. Fossil fuel use and CO2 emissions in Korea: NEAT approach. Resour. Conserv. Recycl. 2005, 45 (3), 295-309.

(44) Motta, S. La; Santino, D.; Ancona, P.; Weiss, M. CO2 emission accounting for the non-energy use of fossil fuels in Italy: A comparison between NEAT model and the IPCC approaches. Resour. Conserv. Recycl. 2005, 45 (3), 310-330.

(45) Weiss, M.; Neelis, M. L.; Blok, K.; Patel, M. K. Non-energy use and related carbon dioxide emissions in Germany: A carbon flow analysis with the NEAT model for the period of 1990-2003. Resour. Conserv. Recycl. 2008, 52 (11), 1252-1265.

(46) Neelis, M.; Patel, M. K.; Blok, K. CO2 emissions and carbon storage resulting from the non-energy use of fossil fuels in the Netherlands, NEAT results for 1993-1999. Resour. Conserv. Recycl. 2005, 45 (3), 251-274.

(47) IPCC. Revised 1996 IPCC Guidelines for National Greenhouse Gas Inventories; IPCC/OECD/IEA: Paris, 1997.

(48) Kram, T.; Gielen, D. J.; Bos, A. J. M.; de Feber, M. A. P. C.; T, G.; Groenendaal, B. J.; Moll, H. C.; Bouwman, M. E.; Daniels, D. W.; Worrell, E.; Hekkert, M. P.; Joosten, L. A. J.; Groenewegen, P.; Goverse, T. The MATTER Project: Integrated Energy and Materials Systems Engineering for GHG Emission Mitigation; ECN, Energy Research Centre of the Netherlands: Petten, NL, 2001. 
(49) Groenendaal, B. J.; Gielen, D. J. The Future of the Petrochemical Industry: A MARKAL-MATTER analysis; ECN; Energy Research Centre of the Netherlands: Petten, NL, 1999.

(50) Joosten, L. A. J.; Hekkert, M. P.; Worrell, E. Assessment of the plastic flows in The Netherlands using STREAMS. Resour. Conserv. Recycl. 2000, 30 (2), 135-161.

(51) Gielen, D.; Newman, J.; Patel, M. K. Reducing Industrial Energy Use and CO2 Emissions: The Role of Materials Science. MRS Bull. 2008, 33, 471-477.

(52) Ayres, R. U.; Talens Peiró, L.; Villalba Méndez, G. Exergy efficiency in industry: Where do we stand? Environ. Sci. Technol. 2011, 45 (24), 10634-10641.

(53) Geyer, R.; Jambeck, J. R.; Law, K. L. Production, use, and fate of all plastics ever made. Sci. Adv. 2017.3e170078210.1126/ sciadv. 1700782

(54) Griffin, P. W.; Hammond, G. P.; Norman, J. B. Industrial energy use and carbon emissions reduction: a UK perspective. WIREs Energy Env. 2016, 5, 684-714.

(55) Brown, T.; Florin, N.; Fennell, P. Briefing Paper No. 7: Reducing $\mathrm{CO} 2$ emissions from heavy industry: A review of technologies and considerations for policy makers. Grantham Inst. Clim. Chang. Brief. Pap. 2012, No. No. 7, 32.

(56) IEA. Energy Technology Transitions for Industry: Strategies for the Next Industrial Revolution; OECD/IEA: Paris, 2009.

(57) PlasticsEurope. Eco-profiles and Environmental Product Declarations of the European Plastics Manufacturers: Styrene Acrylonitrile (SAN) and Acrylonitrile Butadiene Styrene (ABS); Plastics Europe: Brussels, Belgium, 2015.

(58) PetrochemicalsEurope. Petrochemicals Europe - What is it and who belongs to it? http://www.petrochemistry.eu/who-we-are/aboutpetrochemicals-europe.html.

(59) Schmidt, M. The Sankey diagram in energy and material flow management: Part I: History. J. Ind. Ecol. 2008, 12 (1), 82-94.

(60) Schmidt, M. The Sankey diagram in energy and material flow management - Part II: Methodology and current applications. J. Ind. Ecol. 2008, 12, 173-185.

(61) Soundararajan, K.; Ho, H. K.; Su, B. Sankey diagram framework for energy and exergy flows. Appl. Energy 2014, 136, 1035-1042.

(62) Brunner, P. H.; Helmut, R. Pratical Handbook of Matreial Flow Analysis; 2011.

(63) METI. Future Supply and Demand Trend of Petrochemical Products Worldwide; Ministry of Economy, Trade and Industry: Tokyo, Japan, 2016.

(64) Bioplastics Facts and Figures; European Bioplastics: Huerth, Germany, 2015.

(65) Shen, L.; Worrell, E.; Patel, M. Present and future development in plastics from biomass. Biofuels, Bioprod. Biorefin. 2010, 4 (1), 25-40.

(66) ECHA. European Chemicals Agency; Information on Chemicals https://echa.europa.eu/information-on-chemicals (accessed January 30, 2017).

(67) Amar, I. A.; Lan, R.; Petit, C. T. G.; Tao, S. Solid-state electrochemical synthesis of ammonia: A review. J. Solid State Electrochem. 2011, 15, 1845-1860.

(68) Saygin, D.; Patel, M. K.; Tam, C.; Gielen, D. J. IEA Information Paper: Chemical and Petrochemical Sector; OECD/IEA: Paris, 2009.

(69) Methanol Institute. IHS Chemical Profile http://www. methanol.org/the-methanol-industry/ (accessed January 30, 2017).

(70) Appl, M. Ullmann's Encyclopedia of Industrial Chemistry: Ammonia, 3. Production Plants. In Ullmann's Encyclopedia of Industrial Chemistry; 2011.10.1002/14356007.a02_143.pub3

(71) Rainer, R.; Marschner, F.; Renner, H.-J.; Boll, W.; Supp, E.; Brejc, M.; Liebner, W.; Schaub, G. Ullmann's Encyclopedia of Industrial Chemistry: Gas Production, 2. Processes. In Ullmann's Encyclopedia of Industrial Chemistry; 2011.10.1002/14356007.o12 o01

(72) IEA; OECD. Eurostat. Energy Statistics Manual; OECD/IEA: Paris, 2005.

(73) Clark, J. The Haber Process http://www.chemguide.co.uk/ physical/equilibria/haber.html.
(74) Wells, G. M. Handbook of Petrochemicals and Processes, 2nd ed.; Ashgate, 1999.

(75) Koottungal, L. Special Report: International survey of ethylene from steam crackers - 2013; Oil Gas J., 2013.

(76) Koottungal, L. Special Report: International Survey of Ethylene from Steam Crackers - 2014; Oil Gas J. 2014.

(77) EC. Best Available Techniques (BAT) Reference Document in the Large Volume Organic Chemical Industry; 2017.

(78) Bender, M. An Overview of Industrial Processes for the Production of Olefins - C4 Hydrocarbons. ChemBioEng Rev. 2014, 1 (4), 136-147.

(79) Bender, M. Global Aromatics Supply - Today and Tomorrow. Oil Gas Eur. Mag. 2013, No. No. 4, 209-212.

(80) Burdick, D. L.; Leffler, W. L. Petrochemicals in Nontechnical Language, 4th ed.; PennWell, 2010.

(81) EC. Best Available Techniques (BAT) Reference Document in the Large Volume Inorganic Chemicals - Solids and Others industry; 2007.

(82) Solomon Associates. Solomon Benchmarking: Worldwide Olefin Plant Performance Analysis https://www.solomononline.com/ benchmarking/chemicals/olefin-study (accessed January 30, 2017).

(83) Textile World. Man-Made Fibers Continue To Grow http:// www.textileworld.com/textile-world/fiber-world/2015/02/man-madefibers-continue-to-grow/ (accessed January 30, 2017). 